\title{
English for Placement Purposes: Developing a Needs Based Course for Meeting the Employment Demands of IT Industries
}

\author{
Jabbar Al Muzzamil Fareen a * \\ ${ }^{a}$ SRM University, Department of English \& Foreign Languages, Kattankulathur, Tamil Nadu, India
}

Received 22 September 2016 | Received in revised form 11 December 2016 | Accepted 9 January 2017

\begin{abstract}
The instrumentality for conducting a specific needs based placement course in an engineering programme is to develop relevant employability skills of the technical students to cater to the communicative demands of the industry. This paper is concerned on understanding tertiary level students' language and communication problems while they face job interviews. This article is treated with triangulated multiple sources and methods to analyze the learning needs of the final year Information Technology students and the target demands of the HR Managers. It is found that the technical students need to adopt relevant job related oral and written communication skills to competently perform in on-campus recruitments. With the due emphasis given on examining present and target situational needs, a specific needs based intensive communicative course is designed and developed to satisfy the learners' learning needs and their target situational demands. It reports on how the technical students are able to satisfy the recruiters in their job interviews.
\end{abstract}

(C) 2017 EJAL \& the Authors. Published by Eurasian Journal of Applied Linguistics (EJAL). This is an open-access article distributed under the terms and conditions of the Creative Commons Attribution license (CC BY-NC-ND) (http://creativecommons.org/licenses/by-nc-nd/4.0/).

Keywords: English for Placement Purposes (EPP); English Proficiency Course (EPC); on-campus recruitment drive; needs analysis; productive skills; syllabus design

\section{Introduction}

With the spread of globalization and the expansion of Multinational Corporation (MNC) and Information Technology Enabling Service (ITES) companies, technical students are in the urge to develop relevant employability skills to enter into their domain industry. English communication skills have been considered as the core component for providing placement training programs in the engineering colleges of India. In India, technical institutions employ the placement training and development cell to provide job relevant skills based training to the third and final year engineering students. Most technical institutions organize job fairs for on-campus recruitment by inviting reputed companies to recruit their eligible wards with a notable designation and pay. Technical students realize the importance of

\footnotetext{
* Jabbar Al Muzzamil Fareen. Tel.: +0-000-000-0000

E-mail address: jamfareen2006@yahoo.com

http://dx.doi.org/...
} 
communicating in English in every sphere of their business life (Crossling \& Ward, 2002; Radzuan \& Kaur, 2010). Besides managerial and technical skills, they are more conscious in developing their language and communication skills to seek a better position in the open job market and in on-campus recruitments. As English communication has become the essential requirement to enter any profession, the aspiring technical students recognize the need to competently communicate in both oral and written forms.

Self-financing professional and technical colleges have realized that it is mandatory to conduct an English proficiency course for the technical students to seek placement in the on-campus interviews. Though the placement task is administered by the placement and training faculty, language and communication training is exclusively done by the concerned English faculty of the respective departments. The English faculty is solely responsible for framing the curriculum and designing the syllabus for developing a needs-based course for English for Placement Purposes (EPP). This research presents a framework for designing and developing an English Proficiency Course (EPC) for technical students to enhance effective English communication skills to meet the employment demands of the industry.

\subsection{Background to the study}

English for Specific Purposes (ESP) courses have been essentially conducted worldwide to satisfy the specific needs of the learners in both academic and professional contexts. The global use of English language in varied workplace contexts has provided ESP to be the most emerging trend of language learning today (Basturkmen, 2012; Esteban \& Canado, 2004; Eyring, 1998; Lockwood, 2012; Wongsothorn, 2002). The specific purpose for learning English and the needs of the students in their present and target demands can be investigated through conducting needs analysis (Hutchinson \& Waters, 1987; Munby, 1978; Widdowson, 1983). Needs analysis is the process of analyzing learner and learning needs in the present and target communicative situations. It serves as a necessary tool in syllabus design for analyzing the purpose, product and process specifications of language learning. Brindley (1989), Berwick (1989), St. John (1996), Huh (2006), Cowling (2007) and Kayi (2008) affirmed the significance of conducting needs analysis in developing needs-based ESP courses. Hutchinson \& Waters (1987) described the significance of target situation analysis and discriminated the distinction between present learning needs in the academic settings and professional language needs in the target situation.

The notion of 'why' to conduct needs analysis is purely a matter of consideration of learning a language for specific purposes (Flowerdew, 2005; Jackson, 1998; Xu yunZhu, 1999). What type of needs analysis needs to be undertaken in what contexts is one of the major underlying questions probed for understanding the purpose of language learning (Edwards, 2000; Oanh, 2007; West, 1994). Students' likes, wishes, wants, expects, lacks, perspectives, aspirations, beliefs, interests and learning styles 
are the varied constructive factors used in analyzing the personal or subjective needs of the learners (Bacha \& Bahous, 2008; Myhill \& Jones, 2007; Petric, 2005; Taillefer, 2007; Toh \& Hocking, 2010). It reflects on understanding the present learning situation and describes the use of means or process oriented language learning (Dovey, 2010; Nunan, 1996). The expectations, demands and requirements of the target workplace context are reflected as objective needs. It focuses on employing goalbased or product oriented language learning (Holme \& Chalauisaeng, 2006; Hyland, 2003; Kamimura, 2000).

Needs analysis aims at clearly exemplifying the objectives, goal, content, teachinglearning methods and evaluation procedures for designing the syllabus of the course (Cowling, 2007; Huh, 2006; Nkosana, 2008; St. John, 1996; Yalden, 1987). It is the process of conducting preliminary research for identifying and analyzing the language needs of the students and industry (Bacha \& Bahous, 2008; Bosuwon \& Woodrow, 2009; Flowerdew, 2005). Content specification, methodological and pedagogical notions can be thoroughly developed through the findings of the needs analysis (Cowling, 2007; Dolton \& Vignoles, 2002; Spratt, 1999). In the process of language learning, students' deficiency analysis is relatively important as it helps to understand the present learning situation and examines the pedagogical needs in the construction of ESP courses. Brindley (1989) and Berwick (1989) defines gap analysis as the process of analyzing learners' lacks and learning deficiencies in the present situation. Gap analysis is instrumental in the process of language learning as it identifies the performances of the students and enables them to develop relevant target level skills and competencies in the present situation. Wongsothorn (2002) emphasizes on employing experiential learning strategies to develop both personal and professional communication. Nunan (1988), Widdowson (1990), Ho (1997), Jackson (1998), and Atai and Nazari (2011) observed the practical challenges and issues related to classroom management, teachers' and students' language awareness, methods and techniques involved in language learning.

In designing and developing an ESP curriculum, Jassem \& Jassem (2002), Kayi (2008) and Atai \& Nazari (2011) observed the role of language and linguistic variables like grammar, vocabulary and pronunciation, and considered listening, speaking, reading and writing skills as equally important for enhancing effective communication skills. With his investigation on Students' Analysis (SA), Rizvi (2005) found peer response and feedback provides insight on learner participation and in developing public speaking skills for oral business communication. Ting (2002) suggested the substantial use of oral skills for the support staff in the workplace. Esteban and Canado (2004), Zhu (2004), Bruce (2005) and Petric (2005) visualized written tasks for developing academic and business genres. Nickerson (1998) examined the use of English in business writing and discusses on how it affects the corporate culture within the British subsidiaries in the Netherlands. In a case study of two EAP programmes conducted at the two universities in New Zealand and Vietnam, Oanh (2007) found that formal needs analysis practiced in New Zealand University be a model to the Vietnam university as it practiced informal needs 
analysis. Jasso-Aguilar (1999) found informal communication as the vocational needs of Waikiki hotel maids as they can engage in casual chatting with their guests and the customers. As the use of vernacular or bilingual interactions has been a cause of Japanese professors' and students' limited English language use, Manakul (2007) investigated the professional use of English communication as the dire need to engage in formal discussions. In investigating the needs of the employees of Japanese company, Mitsubishi Heavy Industries, Cowling (2007) found content, skills, topic and task based syllabus as the immediate requirement to design a course.

The research findings of Li So-mui and Mead (2000), Crossling and Ward (2002), and Radzuan and Kaur (2010) reflected the frequency of oral communication in the workplace and its significant use in the process of recruitment, job stability, success and promotion. Kim (2006) identified individual, small group discussions and whole class discussions as the most frequently required oral classroom tasks for developing listening and speaking skills in non-science and non-engineering East Asian graduate students. Bacha and Bahous (2008) discussed the written language ability of the business students and stressed the role and significance of English and business faculty in developing students' business writing skills in the business majors. In an ESP program conducted to the mixed level students, Yogman and Kalyani (1996) stressed on providing independence and interest to the students' self-selection and self-preparation of the topic and content to engage in open tasks that caters to the need of academics and employment.

\section{Method}

The purpose of the present research is to develop a needs-based course for final year technical students to cater the industrial demands on employability. With the specification of purpose, product and process orientations, this study focuses on designing and developing a needs-based course for seeking placements.

\subsection{Context and course of the study}

In purview to design and develop a needs-based placement course, the present research attempts to primarily conduct needs analysis to examine the language and learning needs of the technical students and their professional demands in the industry. A communicative course on placement is conducted in the third year of the undergraduate engineering programme. This course is a practical laboratory programme conducted through two components - language lab and career lab. Language lab is truly doing some justice to a reticent student, who delves upon the computer machine to learn language, rather than to interact with the peers. It stimulates autonomous learning and makes the student to involve in exercising grammar, vocabulary and pronunciation tasks. As the teacher monitors the student through teacher-student console network, the students' progress is assessed with the feedback of the teacher and the inbuilt software assessment. As listening exercises are framed to be time bound, most students had listening and comprehension problems as they are not able to complete the exercise within the stipulated time. 
Students with good proficiency generally become bored as they complete the language exercises very soon. They recognize that the software provided is no more helping them as it is confined with limited grammar and vocabulary tasks. Most students reflect their disinterest to study grammar and wished to indulge in communicative tasks. In the career lab too, the focus is given to PowerPoint presentations, where most students end with reading the slides. Though group discussion has been a popular task among the students where they indulge in discussing their topics of interests, they are not provided with required tables and chairs to sit as a team and discuss in a professional way. Group discussion activities are conducted in the classrooms as they are not provided with an exclusive communication laboratory with sufficient infrastructure. Classroom environment is found to be not feasible due to the use of mike and the noise prevailed while conducting open tasks.

Students generally prefer to have a full-fledged communicative course where they can improve their discursive skills through job related oral and written tasks. Though, the present academic course aims at providing practice to develop relevant communication skills to seek placement, it is more concerned to develop listening and speaking skills. Students realize that they need to undertake an intensive interactive communicative course that helps them to acquire relevant employability skills and to sustain their career prospects in their domain industries. As the present academic course is not constructed on the grounds of needs analysis, students' contextual needs are not thoroughly examined. And moreover, the present and target situational demands are not updated. The students' lacks and deficiencies are not carefully followed and the remedial measures are not treated throughout their study in the academic course. As the recruitment process and procedures are not found to be static in all the companies, the teachers and students need to have considerable knowledge and awareness about the recruitment ideologies of various companies. These factors affected to conduct a research to design a specific needs based course with an updated syllabus to meet the existing employment demands of the industry.

In King College of Technology, India, the instigation for conducting English proficiency course is a matter of urgency as most students felt that they needed a supplementary course for developing English communication skills. This selfmotivation and language awareness of the students to learn English language and communication skills for seeking placements helped the English faculty to conduct needs analysis and design a course that satisfies the requirements of both present and target situation. This research study is a positive joint venture on identifying the participation and reflection of students, language and subject faculties and Human Resource Managers' (hereafter referred HR Managers) perception of the language and learning needs and in meeting the demands of recruiters and the challenges to sustain on the job.

\subsection{Participants}

Final year B.Tech. Information Technology (IT) students (65), English Head and faculties (3) including researcher acting as a participant observer, IT Head and 
faculties (2), placement faculties (3), college Principal and Management and HR Managers (9) are the multiple sources used for collecting the data for analyzing the needs, wants, expectations and demands of the students, institution and industry. Most students hail from cosmopolitan and heterogeneous backgrounds as they significantly vary in context to their location, board of higher school studies, language and culture. Students' level of English language proficiency varies as some students have a serious lacuna in expressing their views in both speaking and writing. The boys (44) and the girls (21) are well coordinated in terms of their interests and study. Most students are aged 20 and some 21. All the HR Managers are well informed in their job domains and have sought more than twelve years of professional experience in their respective companies. All the faculties are experienced more than seven years in teaching and one of the placement faculties has sought four years of industrial experience, added to teaching. Both the management and teaching fraternity are proactive in addressing the levels of students' language proficiency, communicative ability and their competency to face the recruitment boards. As the final year IT students are in the verge of completing the course and much aspired to seek oncampus placements, this study is carried out in the seventh semester of the course. To sustain the ethical standards of the research and the stakeholders' confidence, most participants are referred anonymously and the faculties are referred with pseudonyms.

\subsection{Data collection and analysis}

Needs assessment was undertaken with the seventh semester, final year B. Tech. IT students of King College of Technology, India. A qualitative ethnographic mode of communicative needs and demands analysis are administered to understand the actual needs of the students and the workplace demands. Ethnographic approach to qualitative research is essential as this study employs varied sources to reflect on their personal and professional experiences in context to education and profession. Further, the participant observation and the interpretation of the stakeholders will help us to understand the prevailing culture in the academics and workplace. Formal and informal discussions, unstructured interviews, classroom observations, selfassessment, peer response and feedback are the multiple methods used to examine this qualitative survey (Berwick, 1989; West 1994). Conducting needs analysis through ethnography is instrumental to understand the personal reflections of all the stakeholders involved in the research (Crossling \& Ward, 2002; Oanh, 2007). As needs analysis is a continuous process, English faculties had to conduct repeated discussions with the students, subject faculties, placement coordinators and HR managers in both on and off office time hours. As to acknowledge to understand the "what" and "how" of the course, it has taken three weeks for the faculties to specify the content and method of the course. This is essentially a utility based research as it encompasses the emic and etic perspectives of the participants for analyzing students' learning needs, and designing and developing a process and product based course that helps them to enhance employability skills. 
The Head of the Department of Information Technology recognized that the IT students should develop a knack to competently communicate in English and hence entrusted English department to conduct a special course for developing English proficiency skills of their final year, B. Tech. IT students and urged to help them seek placements in the on-campus recruitment drives. The English Head had a formal discussion with the IT Head and placement coordinators as they are very much concerned in revealing their interests and understanding students' performances in job interviews. The two faculties of the IT department, who coordinate placement activities, shared their perceptions on their students' communicative needs. It was suggested that four students of excellent academic records and six average students can be interviewed to understand their language learning needs and expectations for the present recruitment drive. The English faculties had both formal and informal classroom discussions and casual interactions with the IT students to observe their language awareness, intentions and interests in language learning.

The present research is further extended to proceed with the formal discussions held with the HR Managers to understand their prolonging demands on the use of effective language and communication skills. A research mapping was done to understand the mode of the recruitment process, conducting placement tests and interviews. With the aid of pilot study conducted through unstructured interviews and discussions, needs assessment is undertaken to design EPC. The major findings of the pilot study is that the students are mainly deprived with language productivity as they are unable to express, share or discuss their views in interpersonal tasks. Hence needs based language learning has become quintessential in understanding the purpose and process of language education. In conjugation to satisfy the academic and workplace needs, the purpose of language learning and the content of the course are specified through the participants' responses taken from both interviews and discussion. Class observation, self-assessment, peer response, and feedback are simultaneously done in interactive tasks like individual presentations, pair interactions and group discussions. With the help of the active participation of the students in oral and written performances, the faculties are able to observe and record the field notes. This helped them to assess and discuss students' competency levels in the meetings with HR managers. The process of language learning is closely examined as a gap analysis was undertaken to analyze the performances of the students throughout the course.

\section{Findings and discussion}

All the stakeholders involved are found to recognize the due importance given for conducting a needs-based course for placement purposes. The final year technical students considered that they need to get through group discussions for the final selection of the job interviews. All of the selected students (10) expressed their willingness to communicate in English through learning a special course to develop their employability skills. In the class committee meetings held with the students, it was confirmed that the students are not particularly exposed to speaking tasks like 
group discussions and job interviews. The formal and informal discussions with all the students in the classroom and department helped to realize that the students have general awareness of English communication and its predominant use in placements.

Student1 revealed the significant use of English in the recruitment process,

English is basically important to participate in group discussions and job interviews. English is must to get get employment in multinational companies.

Student8 remarked the predominant use of English in both academic and professional contexts,

English is so compulsory to learn that we use English for all studies and work. If you know English, you can learn and pass the exams, you can get the jobs in good software companies. So automatically, we try to speak in English to get our dream jobs.

Most students specifically claimed the inclusion of sufficient language and communication training in their expected placement course,

We need language training. We should know how to present at the interview. We are not trained in group discussions.

Though we prepare topics for presentation and group discussion, we need sufficient time and guidance to practice with our friends.

We need to have several trial sessions before we face the placement rounds. This will increase our confidence level and to understand the procedures in facing the interview board.

Because I'm not efficient in speaking and using English, I wish to improve my speaking skills. It can express my personality and talent in the interview.

I wish to learn how to communicate with professional persons and social persons. I need to know email writing, formal and informal and to prepare an attractive resume and how to prepare for an interview and how to present ourselves to the interviewers.

I wish to develop my technical presentations through self-preparation and self-learning. But when coming to talk on any current affairs or on any group discussion topics, I prefer to prepare the topic with my friends. I wish to be involved in group learning.

The students generally recognized that they need to be specifically trained in discursive skills. In a formal meeting with the IT Head and the faculties, it is resumed that most students are not good at speaking, particularly in expressing their views and to respond immediately in English. It is commonly noted that though the students have passed their disciplinary subjects without any arrears they are not prepared to speak in English. Gauthaman, an IT faculty revealed that the students are not exposed to business communication. Savitha, an IT faculty further commented that the students' lack of preparation to communicate in English has been the major drawback for them for not attending the recruitment drives. Gowri, another IT faculty continued that all the students need to be placed in the on-campus placements, otherwise it will be very difficult for the students to get the job placements in the open job market. The IT and English Head expressed their consent to teach business English and interpersonal skills as they need to successfully convince and negotiate their interviewers,

They should develop their speaking skills. They should be able to present and negotiate their ideas. They should be able to answer interview questions in the final round.

While discussing the students' potentialities in facing the recruitment drive, HR Manager1 stressed the importance of informative knowledge in communication, 
Students need to express their knowledge in the topic referred. They are unable to put their ideas with clarity and precision. They are neither good in language nor in communication. If only they communicate, we can understand the stuff about the product, they are not able to produce appropriate language.

HR Manager6 flashed that the technical students need to confidently communicate in English,

Till how far the college will say that the $3 / 4$ of the student population hails from the remote villages and possess little access to a sound literary background. How come they will get excuses by saying the students hail from Tamil medium (vernacular medium)?

The formal and informal discussions and interviews with the IT students, IT Head and faculties and HR Managers revealed that communicating in English is a prerequisite. The notions of technical students substantiated the view that to further improvise their communication skills in English and to get through the recruitment process, a needs-based English proficiency course is mandatory in the final year of their professional education. IT Head and faculties and HR Managers considered that a special communicative course is quintessential to provide placement training to the students.

With the aid of conducting needs analysis, the purpose, product and process specification of the course can be determined. As the objective of the proposed course is to develop employability skills, the technical students specified that they need to essentially improve English communication skills for seeking placement. All the stakeholders specifically insisted that they need to incorporate language skills and content based learning. As it is suggested the students need to possess disciplinary technical knowledge with speaking and writing genres, skills and tasks, the present syllabus is specified with the content, methodological and pedagogical orientations to satisfy the specific needs of the course. The Figure 1 given below shows the framework of a needs-based ESP course developed through the administration of needs assessment, syllabus design through process and product orientations and course revision.

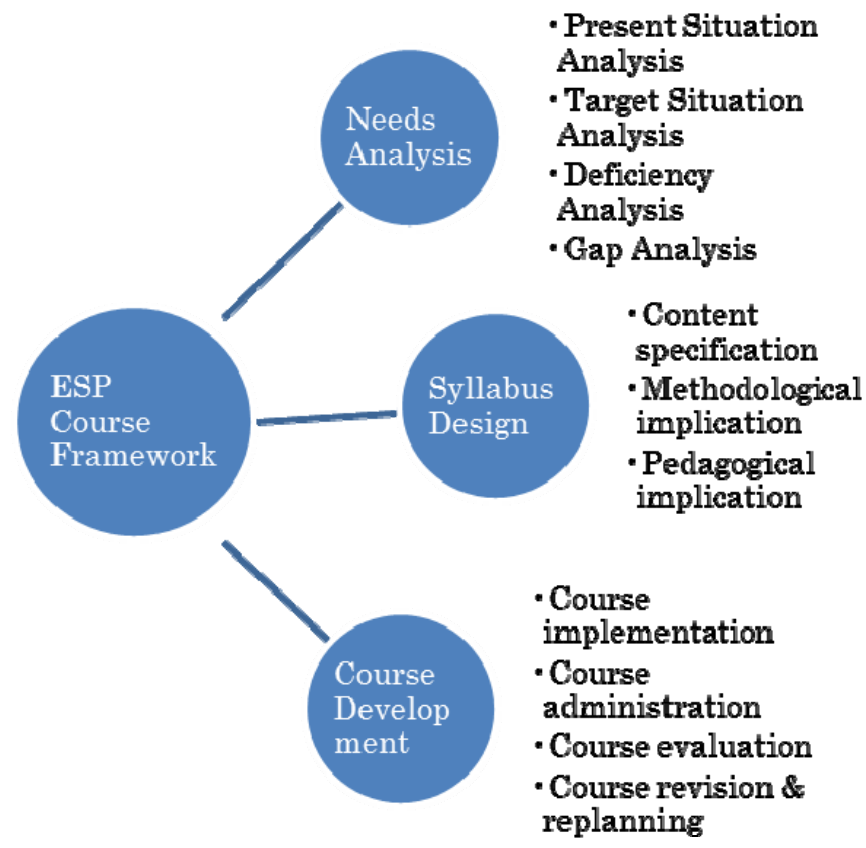

Figure 1. ESP Course Framework 
Needs analysis is essentially beneficial in analyzing the lacks and deficiencies of the students. It also makes apparent about the students learning difficulties and reflects on their strategies, preferences and styles in language learning. The pedagogic needs can be better analyzed through the observation of gap analysis conducted throughout the course. The process of needs analysis conducted through formal and informal discussions and interviews helped to design the syllabus framework in specifying the content, method, teaching and learning of the course. It has also provided guidelines for the formative and summative evaluation of the course. Thus this course is developed through the progressive stages of implementation, administration and evaluation (White, 1988). The revision and replanning of the course can be again undertaken and updated through conducting needs analysis.

Contextual situation analysis is undertaken to examine what actually the students require in the English proficiency course. The students generally realized that they lack adequate communication skills and they are not able to use English for communication due to lack of grammar and vocabulary. The most often demanded activities of the HR Managers are oral presentation, group discussion and job interviews. Almost all the HR Managers share that in order to test speaking skills, group discussion and interview are found compulsorily in all the recruitments. According to the HR Manager3,

Speaking is the most wanted skill. We have to test the prospective candidate only on the basis of their performance in group discussion and interview.

The HR Manager2 acknowledged that if the workplace positions specifically demands on writing skills and if they feel that the candidate should be proficient in written business communication, they will definitely conduct a written test on both comprehension and functional writing. Thus, it can be noted that language and aptitude testing is done in the preliminary stage and subsequently, oral presentation, group discussion, and interview will be compulsorily conducted at any recruitments and this forms the basic content of the present course.

A speaking and writing module is prepared with the objectives of meeting the placement requirements. The students are given trial rounds to perform interactional activities to develop their speaking skills and they are motivated how to convince and negotiate their ideas in substantiating their views on any topic. The degree of subject knowledge, relevant topic and information content is crucial for a successful oral and written presentation as it reflects the productive ability of an individual. To cater the writing needs of the students, drafting a CV with application, business letters, emails, report and project writing are encouraged. A special focus is given on developing appropriate language use in both oral and written communication. As the recruitment procedures are widely based on testing speaking and writing skills, the course is specifically meant for developing language and communication skills in context to skills, genres, tasks and situations. In purview to develop the speaking and writing abilities of the students, this course is specified with the interpersonal and group 
communication tasks. Further, the course is detailed through the contextual use of speaking and writing genres as mentioned below.

\section{Course Description}

\section{Speaking Module}

1. Free conversation - self-opted topic presentation

2. Technical topic with power point presentation

3. Group discussion (Topics to be negotiated with the faculty)

4. Group discussion (Topics related with social and cultural issues)

5. Self-introduction - narrating Curriculum Vitae (CV)

6. Job interviews

\section{Writing Module}

1. Writing a letter of application with CV

2. Process description - general, scientific and technical

3. Business and report writing

4. Project proposal

5. Mini project writing

6. Technical article writing

With a careful analysis done on communication needs and demands of all the stakeholders involved in the study, this abridged program on English proficiency is planned and designed for fifteen weeks in the seventh semester of the final year, B. Tech IT course. A total of 6 hours with 3 hours each is weekly conducted as practical for developing communication skills. This course is not confined only to the class hours. Additional coaching classes were conducted when any on-campus recruitment drive is conducted in the college. It can be further noted that a total of 90 hours is planned in three phases of communication development. The Fig. 2 given below specifies learning process analysis as it depicts the learning experiences of the students and their gradual development and use of language, discursive skills and learning strategies for gaining communicative competence.

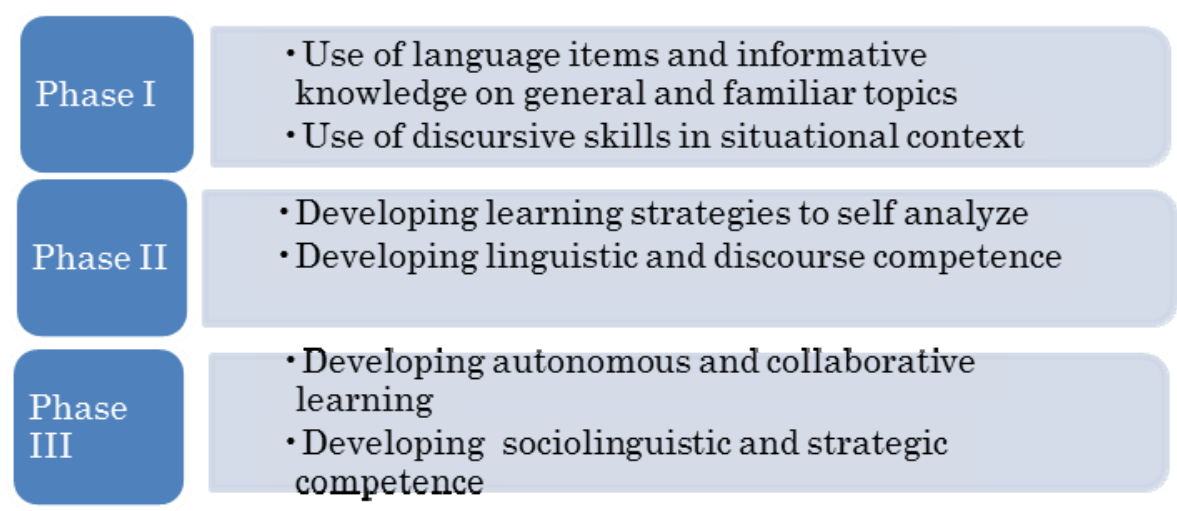

Figure 2. Learning Process Analysis 
In the first phase, it is expected that the technical students need to be familiarized with oral and written genres, skills and tasks. They are also expected to be literally expressive and communicative to use the language and put their ideas in thought and action. Language and subject faculties monitored the students to develop their competency skills. Their critical insight and feedback on the students' performances in the classes helped to understand their gradual improvement in the due course of the study. Student4 affirmed the importance of speaking skills for facing the recruitment panel,

We are used to read and write to prepare for exams, but now for to prepare an interview, we should speak. And speaking is very difficult. Speaking means originally talking about the ideas and I cannot speak continuously. So, I should develop speaking skills to face the interview.

Student6 anticipated for developing both oral and written communication skills,

Writing is also important, we are not able to originally write business letters and e-mails. I should originally speak and write. To develop my vocabulary, I read newspapers and dictionaries. But still, I am not communicating.

Students need to considerably possess adequate informative knowledge on relevant topics and theme. They should be able to display their technical subject knowledge with appropriate language skills. When the candidate seems to be below average and uncomfortable in dealing with the approved topics, they are encouraged to select even some general and familiar topics to speak on. The central idea of the course is to make the candidate to speak, and errors are permitted in the first phase of the two rounds of the presentation. But gradually, the student is screened for writing appropriate language and expected to make use of refined language in all the oral and written tasks. It is anticipated that all the students should be capable enough to engage in interactional discourse.

The second phase is entirely focused on developing learning strategies to improve language and communication skills. That is, linguistic and discourse competence should be equally balanced along with the gestalt notions. In the second phase, the students are instructed about the remedial use of grammar, vocabulary and meaning and the use of the content and context based discourse. The students are examined to self-analyze their lacks in information and communication. Appropriate language and communication strategies are applied to make the students realize what actual mistakes they have committed, what are their lacks and deficiencies and what actually they have to learn in the course. The students are monitored to consistently practice oral and written genres. And they are also trained to competently communicate with adequate structures and discourse. They are also informed and counselled to understand about the opportunities and pitfalls found in the recruitment process.

In the third phase, students are found to indulge in both autonomous and collaborative learning tasks. They are found to be keenly interested in participating themselves in small talk, discussions, presentations and interviews. Students are advised to make distinct use of skills, tasks, genres, topics and content for both 
planned and extempore presentations. This is highly useful when they are able to react to the incidental responses in group discussions. From time to time observations recorded in the class, it is usually found that the students who are able to present ideas with authentic references and citations are able to coordinate and dominate in group discussions. They are able to exhibit their discourse and strategic competence in leading discussions and interviews. The students are found to be cooperative and informative in gradually preparing and presenting the topic and content. These attitudes and skills are reflected in the actual recruitment process. It is specifically focused that the students need to possess adequate grammatical and discourse competence and should be able to display sociolinguistic and strategic competence to communicate in any situational contexts. Most students shared their views on how they have improved their performances through this course, This course has helped me to improve my speaking, reading and writing skills through group
discussion and presentation of seminars and browsing the internet. Through this I have developed
my technical presentation skills. I am able to face campus interviews through group discussions
and presentations.

This syllabus has helped us to improve our business communication skills. We are able to write advanced email business letters and technical reports.

With the help of this syllabus, I learn new techniques and how to select the topics, how to present the ideas with my friends in better way. Now, I am aware about how to write and present some topics without making any mistakes.

This course helped me to develop the skills by the use of conducting seminar and projects. The teachers have helped me to interact and to perform individually. This practice of my individual and group performances helped me to get job.

This course improved my speaking skills. Now I am confident to attend any interviews and group discussions. Writing skills helped me to express my ideas as my reports and articles are found to be good by the teachers. Listening and reading skills are also improved as I collect more ideas to discuss on presentations.

I have improved my soft skills; I remove my fear while speaking on stage and also improved my gestures. I have the ability to speak without any stress or delay because of the exercises conducted such as oral presentation and group discussion. And also I am able to listen others' views and ideas.

This course has helped me to improve my communication skills in English. I feel better now from stage fear. I practice every day to improve my body language and speaking skills.

For getting rid of the mistakes in our language we should first speak it with our friends. So our friends could help us in identifying our mistakes. Writing helps us to improve our thinking capacity and helps to improve our knowledge.

Self-analysis, peer review and teacher's feedback are the major assessment tools used for evaluating performances. The students become confident enough to face both on-campus and off-campus recruitments. Qualified and eligible candidates visited several jobs fair organized by other colleges too. It is overwhelming to know that 16 students are able to get a minimum of three offer letters from various concerns and a total of 49 students are placed in IT companies as 42 students got appointment orders from the Chennai and Bangalore based software companies and about 7 students are placed in the MNC companies. The IT HOD, Principal and 
Management applauded for the students' remarkable performances in the recruitment processes and their subsequent positions offered to them. About 16 students are not placed, as 14 students do not come under the eligibility criteria for having a minimum of one or more arrear in the university exams. Two were the all clear students, but they lack adequate attendance and moreover, they are not sufficiently informative and communicative. The tables 1 and 2 provided below summarize the placement details of the final year IT students.

Table 1. A comprehensive data analysis of placement of the final year IT students

\begin{tabular}{lllll}
\hline $\begin{array}{l}\text { Total no. of } \\
\text { IT Students }\end{array}$ & $\begin{array}{l}\text { Placed in IT } \\
\text { Companies }\end{array}$ & $\begin{array}{l}\text { Placed in } \\
\text { Software }\end{array}$ & $\begin{array}{l}\text { Placed in } \\
\text { MNC }\end{array}$ & $\begin{array}{l}\text { Offered more than 1 } \\
\text { appointment orders }\end{array}$ \\
\hline 65 & 49 & 42 & 07 & 16 \\
\hline
\end{tabular}

Table 2. Data about the IT students who are not placed

\begin{tabular}{ll}
\hline Students ineligible for placements & 14 \\
\hline Students eligible, but not yet placed & 02 \\
\hline Total no. of students not placed & 16 \\
\hline
\end{tabular}

The purpose of conducting EPC is thus ensured through understanding and satisfying the perceptions of all the stakeholders involved in this study. All the technical students persistently revealed that they need to perform oral and written communicative tasks to achieve communicative competency. It is widely acknowledged that communicating in English and performing better with technical and strategic skills is the key to gain success in job markets. As Student7 confessed on getting placement through developing English communication skills,

... with my little language interest and subject knowledge, I always try to communicate in English. I am able to identify my target, as I am able to communicate and get offer letters from two software companies.

The HR Managers are also found to be satisfied with the performances of the students in the oral and written tests and interview. However, they wanted the students to face with confidence and to be really assertive in their mindset. They insisted that soft skills and strategic skills need to be added in the placement training courses. The suggestions and the recommendations of the HR Managers to include soft skills and strategic competency skills are intended to be incorporated in the subsequent revised and updated EPC.

\subsection{Implications of the present study}

This research study entirely focuses on examining the technical students' language and learning needs and emphasizes on developing relevant employability skills to meet the communicative requirements of the industry. All the stakeholders entrust in developing speaking and writing skills for facing the performance based placement screening tests. It is also significantly found that they need to develop receptive skills 
to acquire adequate knowledge and information in their technical disciplines. As information is the core product to be transferred in the process of communication, students need to be more informative and productive on the topic and content to get involved in discursive practices.

With the due awareness given to the student community on the importance of English communication, all the technical students shared their immense interest to learn the corporate language to cope up with the workplace culture. The major implication of this study is to substantiate EPP course to transfer acquired knowledge and skills to the workplace. When the students are asked to self analyze their developments in exhibiting their language and technical knowledge, it is quite understood that they have got good inclination towards listening and reading skills for the data collected on the selected topic in the oral presentations. It is also noted when the students are not able to refer more diverse contents on the selected topic, they are neither able to present the topic nor confidently discuss in any communicative situations. When few students are found to be struggling with limited reading and referencing skills, a general awareness is given that they need to develop extensive reading skills to completely understand and research on the topic. Most students acknowledged the significance of receptive and productive skills as it can be developed through extensive reading and disseminating knowledge through speaking and writing. It is also found that the receptive knowledge cannot be suppressed even though limited language proficiency is seen.

The technical students need to possess adequate cognitive and strategic ability to understand the immediate requirements of the employers and satisfy them through their cognitive and pragmatic competence. The skills to satisfy the employers and the ability to work with time, pace and compete in the professional challenges are generally preferred by all the companies. The industry specifically demands managerial and social skills to up keep both internal and external business relations. Hence, the HR Managers claim that they look for those candidates who are able to articulate their cognitive, technical, managerial and social skills. These requirements are met through interpersonal and group communication tasks where the students are able to reflect their employability skills through emails, reports, small talk, casual interactions, presentations and discussions. As speaking and writing skills are mandatory to face the recruitment process, the students were found keen to develop their communication skills through interpersonal and group communication tasks.

\section{Conclusion}

The present study is a utility based research to understand the specific needs of the technical students and facilitate them to meet the target requirements of the workplace. As the academic courses aim at providing conceptual knowledge in their disciplinary subjects, it little inclines on providing pragmatic skills to transfer their knowledge in the target situation. The transfer of declarative knowledge to procedural knowledge is a challenging process as the students need to excel in rejuvenating their 
skills of expression from academic to the workplace. The present research is necessarily student centered as it focuses on developing the capability of the students to transfer their skills from academic to professional contexts.

\section{References}

Atai, M. R., \& Nazari, O. (2011). Exploring reading comprehension needs of Iranian EAP students of health information management (HIM): A triangulated approach. System, 39, 30-43.

Bacha, N. N., \& Bahous, R. (2008). Contrasting views of business students' writing needs in an EFL environment. English for Specific Purposes, 27, 74-93.

Basturkmen, H. (2012). Languages for specific purposes curriculum creation and implementation in Australasia and Europe. The Modern Language Journal, 96, Focus Issue, 59-70.

Berwick, R. (1989). Needs assessment in language programming: from theory to practice. In R. Johnson (Ed.), The second language curriculum (pp. 48-62). Cambridge: Cambridge University Press.

Bosuwon, T., \& Woodrow, L. (2009). Developing a problem-based course based on needs analysis to enhance English reading ability of Thai undergraduate students. RELC Journal, 40, 42-64.

Brindley, G. (1989). The role of needs analysis in adult ESL programme design. In R. K. Johnson (Ed.), The second language curriculum (pp. 63-78). Cambridge: Cambridge University Press.

Bruce, I. (2005). Syllabus design for general EAP writing courses: A cognitive approach. Journal of English for Academic Purposes, 4, 239-256.

Cowling, J. D. (2007). Needs analysis: Planning a syllabus for a series of intensive workplace courses at a leading Japanese company. English for Specific Purposes, 26, 426-442.

Crossling, G., \& Ward, I. (2002). Oral communication: the workplace needs and uses of business graduate employees. English for Specific Purposes, 21(1), 41-57.

Dolton, P. J., \& Vignoles, A. (2002). Is a broader curriculum better? Economics of Education Review, 21, 415-429.

Dovey, T. (2006). What purposes, specifically? Re-thinking purposes and specificity in the context of the 'new vocationalism'. English for Specific Purposes, 25(4), 387-402.

Dovey, T. (2010). Facilitating writing from sources: A focus on both process and product. Journal of English for Academic Purposes, 9, 45-60.

Edwards, N. (2000). Language for business: effective needs assessment, syllabus design and materials preparation in a practical ESP case study. English for Specific Purposes, 19, 291296.

Esteban, A. A., \& Canado, M. L. P. (2004). Making the case method work in teaching business English: A case study. English for Specific Purposes, 23, 137-161.

Eyring, J. L. (1998). What's an objective anyway? TESL Canada Journal, 15(2), 24-35.

Flowerdew, L. (2005). Integrating traditional and critical approaches to syllabus design: The 'what', the 'how' and the 'why?' Journal of English for Academic Purposes, 4, 135-147.

Ho, B. (1997). Reactions of students to reflective learning in a technical report-writing course. English for Specific Purposes, 16(3), 211-227.

Holme, R., \& Chalauisaeng, B. (2006). The learner as needs analyst: The use of participatory appraisal in the EAP reading classroom. English for Specific Purposes, 25, 403-419. 
Huh, S. (2006). A task-based needs analysis for a business English course. Second Language Studies, 24(2), 1-64.

Hutchinson, T., \& Waters, A. (1987). English for specific purposes: a learning centred approach. Cambridge: Cambridge University Press.

Hyland, K. (2003). Second language writing. Cambridge: Cambridge University Press.

Jackson, J. (1998). Reality-based decision cases in ESP teacher education: windows on practice. English for Specific Purposes, 17(2), 151-167.

Jassem \& Jassem. (2002). English curriculum design: The case of Riyadh college of technology in Saudi Arabia. Issues in Education, 25, 175-194.

Jasso-Aguilar, R. (1999). Sources, methods and triangulation in needs analysis: A critical perspective in a case study of Waikiki Hotel maids. English for Specific Purposes, 18, 27 46.

Kamimura, T. (2000). Integration of process and product orientations in EFL writing insruction. RELC Journal, 31(1), 1-28.

Kayi, H. (2008). Developing an ESL curriculum based on needs and situation analyses: a case study. Journal of Language and Linguistic Studies, 4(1), 29-49.

Kim, S. (2006). Academic oral communication needs of East Asian international graduate students in non-science and non-engineering fields. English for Specific Purposes, 25, 479489.

Li So-mui, F., \& Mead, K. (2000). An analysis of English in the workplace: the communication needs of textile and clothing merchandisers. English for Specific Purposes, 19(4), 351-368.

Lockwood, J. (2012). Developing an English for specific purpose curriculum for Asian call centres: How theory can inform practice. English for Specific Purposes, 31, 14-24.

Manakul, W. (2007). English in Engineering Education for Japanese Graduate Students. Australasian Journal of Engineering Education, 13 (2), 53-63.

Munby, J. (1978). Communicative Syllabus Design. Cambridge: Cambridge University Press.

Myhill, D., \& Jones, S. (2007). More than just error correction: students' perspectives on their revision processes during writing. Written Communication, 24, 323-343.

Nickerson, C. (1998). Corporate culture and the use of written English within British subsidiaries in the Netherlands. English for Specific Purposes, 17(3), 281-294.

Nkosana, N. (2008). Attitudinal obstacles to curriculum and assessment reform. Language Teaching Research, 12, 287-312.

Nunan, D. (1996). Syllabus design. Oxford: Oxford University Press.

Nunan, D. (1988). The Learner-centred curriculum. Cambridge: Cambridge University Press.

Oanh, D. T. H. (2007). Meeting Students' Needs in the two EAP programmes in Vietnam and New Zealand: a Comparative Study. RELC Journal, 38(3), 324-349.

Petric, B. (2005). Contrastive rhetoric in the writing classroom: a case study. English for Specific Purposes, 24(2), 213-228.

Radzuan, N. R. M. \& Kaur, S. (2010). A survey of oral communication apprehension in English among ESP learners in an engineering course. English for Specific Purposes World, 31(10), $1-14$.

Rizvi, M. A. (2005). Using students' analysis in teaching public speaking for business. Profile: Issues in Teacher's Professional Development, 6, 107-118.

Spratt, M. (1999). How good are we at knowing what learners like? System, 27(2), 141-155.

St. John, M. J. (1996). Business is booming: Business English in the 1990's. English for Specific Purposes, 15(1), 3-18. 
Taillefer, G. F. (2007). The professional language needs of Economics graduates: assessment and perspectives in the French context. English for Specific Purposes, 26, 135-155.

Ting, S. (2002). Is English needed in a Malay workplace? RELC Journal, 33, 137-153.

Toh, G., \& Hocking, D. (2010). EAP writing: reflections on divergent perceptions and expectations among tutors and students. Asian Journal of English Language Teaching, 20, 161-183.

West, R. (1994). Needs analysis in language teaching. Language Teaching, 27, 1-19.

White, R. V. (1988). The ELT curriculum, design, innovation and management. Oxford: Basil Blackwell.

Widdowson, H. G. (1983). Learning purpose and language use. Oxford: Oxford University Press.

Widdowson, H. G. (1990). Aspects of language teaching. Oxford: Oxford University Press.

Wongsothorn, A. (2002). Curriculum development research using amplified objectives. RELC Journal, 33, 85-98.

Xu yun-Zhu. (1999). A new ESP course in the present Chinese context. English for Specific Purposes, 18, S57-S74.

Yalden, J. (1983). The communicative syllabus: evolution, design and implementation. Oxford: Pergamon.

Yogman, J., \& Kalyani, C. (1996). ESP program design for mixed level students. English for Specific Purposes, 15, 311-324.

Zhu, W. (2004). Writing in business courses: an analysis of assignment types, their characteristics, and required skills. English for Specific Purposes, 23, 111-135.

\section{Copyrights}

Copyright for this article is retained by the author(s), with first publication rights granted to the Journal.

This is an open-access article distributed under the terms and conditions of the Creative Commons Attribution license (CC BY-NC-ND) (http://creativecommons.org/licenses/by-nc-nd/4.0/). 